\title{
ESWL-assisted removal of a calcified pancreatic
} stent

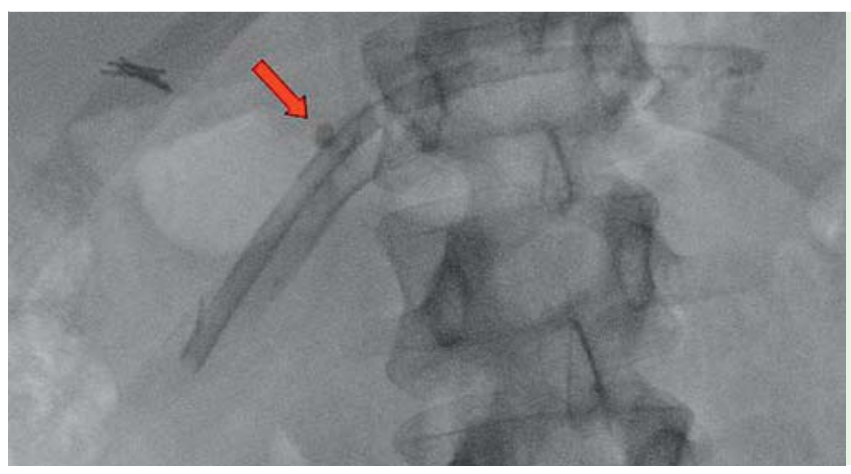

Fig. 1 Calcifications alongside the pancreatic stent (arrow).

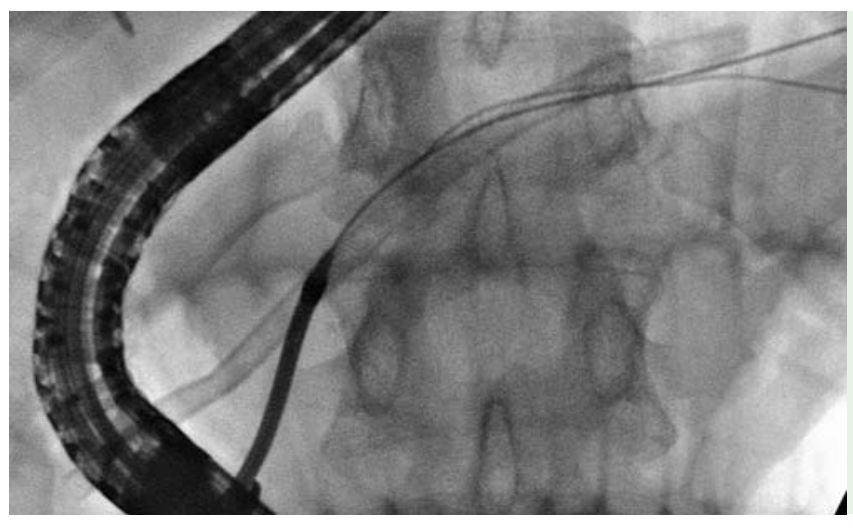

Fig. 2 The 7-French Soehendra stent retriever used as a dilator.
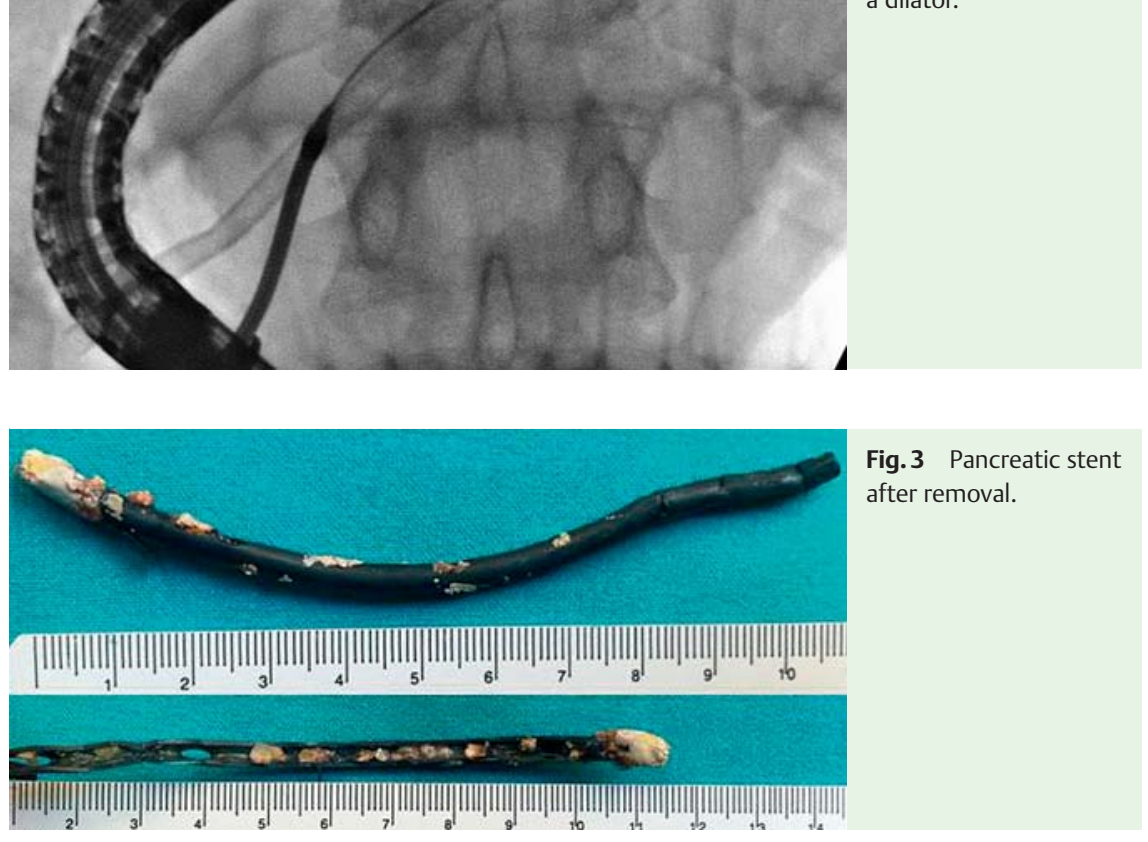

Fig. 3 Pancreatic stent after removal.

A 31-year-old man with calcified chronic pancreatitis underwent extracorporeal shock wave lithotripsy (ESWL) and endoscopic retrograde cholangiopancreatography (ERCP) with pancreatic sphincterotomy and extraction of stones in 2002. A pancreatic stent was inserted because of the presence of pancreatic strictures in the head and body of the pancreas (Cremer type III) [1]. The stent was inserted through the minor papilla owing to a dominant dorsal duct anatomy. The patient experienced symptom relief and underwent symptomatic stent exchange. The last stent exchange was performed in November 2009, when a 9-cm-long, 11.5-French plastic stent was inserted.
Three years later the patient had recurrence of pancreatitis and was referred for stent exchange. A plain radiograph showed calcifications around the stent ( Fig. 1). Several attempts at removing the stent using rat tooth forceps and snare failed. Guide-wire cannulation alongside the stent was possible, but neither mechanical or balloon dilators could be advanced. A 7-French Soehendra stent retriever (Cook Endoscopy, Winston Salem, NC, USA) was also used as a rescue option for dilation [2], but it was able to pass only the cephalic stricture ( $\bullet$ Fig. 2 ). The procedure was interrupted. Two days later ESWL [3] (Lithoskop, Siemens, Erlangen, Germany; 5000 shock waves, power 5, pressure 4) was performed, focusing alongside the pancreatic stent. During a second ERCP the stent was easily removed with a snare ( Fig. 3 ).

In patients with main pancreatic duct strictures related to chronic pancreatitis, symptomatic pancreatic stent exchange can provide pain relief for years, but does carry the risk of complications. In the setting of chronic pancreatitis, planned pancreatic stent exchange is advised. The recent European Society of Gastrointestinal Endoscopy guidelines on the treatment of chronic pancreatitis suggest changing plastic stents within 1 year in asymptomatic patients to prevent complications related to long-standing pancreatic stent occlusion [4].

\section{Endoscopy_UCTN_Code_TTT_1AR_2AB}

Competing interests: None

\section{Bove, A. Tringali, I. Boškoski, G. Gigante, G. Costamagna}

Digestive Endoscopy Unit, Catholic University of Rome, Rome, Italy

\section{References}

1 Cremer M, Toussaint J, Hermanus A. Les pancreatites croniques primitives. Classification sur base de la pancreatographie endoscopique. Acta Gastroenterol Belg 1976; 39: $522-546$

2 Ziebert JJ, DiSario JA. Dilation of refractory pancreatic duct strictures: the turn of the screw. Gastrointest Endosc 1999; 49: 632 635

3 Greiner L, Jakobeit C. ESWL in pancreatic duct stones. Dtsch Med Wochenschr 1989; 114: 1940

4 Dumonceau JM, Delhaye M, Tringali A et al. Endoscopic treatment of chronic pancreatitis: European Society of Gastrointestinal Endoscopy (ESGE) clinical guideline. Endoscopy 2012; 44: 784-800

\section{Bibliography}

DOI http://dx.doi.org/

10.1055/s-0032-1326642

Endoscopy 2013; 45: E163

Stuttgart · New York

ISSN 0013-726X

\section{Corresponding author}

\section{Bove, MD}

Largo A. Gemelli 8

00168 Rome

Italy

Fax: +39-06-30156581

vinbove@alice.it 